\title{
The Development Of E-Module Statistic Course In Building Engineering Education Study Program
}

\section{Pengembangan Modul Elektronik Mata Kuliah Statistika Di Program Studi Pendidikan Teknik Bangunan}

\author{
Haryati Dewi Lastari ${ }^{1}$, R. Eka Murtinugraha ${ }^{2}$, Riyan Arthur $^{3}$ \\ ${ }^{1}$ Mahasiswa Program Studi Pendidikan Teknik Bangunan, Universitas Negeri Jakarta \\ ${ }^{23}$ Dosen Program Studi Pendidikan Teknik Bangunan, Universitas Negeri Jakarta \\ e-mail: dewiharyati076@gmail.com,r_ekomn@unj.ac.id, arthur@unj.ac.id
}

\begin{abstract}
This study aims to develop teaching materials based on electronic modules in the Statistics subject in the Building Engineering Education Study Program, State University of Jakarta that can assist lecturers in delivering course material and make it easier for students to understand the subject matter. The method used in this research is research and development (R\&D) with the development model used is ADDIE. (1) Analysis, (2) Define, (3) Develop, (4) Implementation, (5) Evaluation. This study uses a questionnaire as a tool to test the feasibility of a product by media expert validators and material experts. Product developed is electronic modules consists of 7 material. The results of validation by media experts get an average percentage of $87 \%$ in the "very feasible" category and the results of validation by material experts get an average percentage of $80 \%$ with the "feasible" category. Based on the eligibility results, it can be concluded that the electronic module-based teaching materials in the Statistics course are suitable for the learning process.
\end{abstract}

Keywords: Electronic Module, Statistic, Software Statistic

\section{PENDAHULUAN}

Statistika memberikan manfaat terutama pada bidang pendidikan sebagai alat bantu dalam proses pembelajaran dan juga dapat mengetahui tingkat keberhasilan proses pembelajaran tersebut, sebagai contoh pada penelitian Hutapea yang menganalisis metode problem base learning terhadap ketuntasan hasil belajar [1]. Serta dalam bidang konstruksi Statistika digunakan untuk berbagai aspek seperti pengendalian mutu bangunan, sebagai contoh penelitian Fajrin, dkk. untuk mengetahui komposisi optimal kuat tekan bata non bakar [2]. Oleh karena itu Statistika memiliki berbagai peranan penting pada setiap aspek dunia kerja.

Pada proses pengolahan data penelitian, mahasiswa dapat dibantu dengan penggunaan perangkat lunak atau software, contohnya adalah Microsoft Excel, Microstat dan Statistical Package for Social Science (SPSS). Pada software SPSS menyediakan berbagai fitur pengolahan data yang jauh lebih mudah dioperasikan [3]. Namun, karena kurangnya pemahaman terhadap software tersebut mahasiswa mengalami kesulitan dalam hal pengolahan data dan menyebabkan kekeliruan dalam menggunakannya.

Pada data analisis kebutuhan yang dilakukan di prodi pendidikan Teknik bangunan UNJ menunjukkan bahwa mata kuliah Statistika telah dihubungkan dan diimplementasikan terhadap penggunaan SPSS sebesar 91\%. Namun, mahasiswa yang dapat menggunakan software SPSS adalah 51\% dan mahasiswa yang tidak dapat menggunakan adalah $49 \%$.

Selain itu stigma negatif mahasiswa terhadap mata kuliah Statistika yang dianggap sulit dan membosankan membuat mahasiswa cenderung malas dan berdampak pada pemahaman terhadap materi. Serta dalam proses pembelajaran pada mata kuliah Statistika di Program Studi Pendidikan Teknik Bangunan UNJ menggunakan bahan ajar yang masih terbatas menggunakan Slide Power Point dan Word. Sehingga, menjadikan proses penyampaian informasi materi kurang menarik [4] dan membuat mahasiswa kurang aktif 
karena proses pembelajaran masih terpusat oleh dosen. Sehingga membuat $70,6 \%$ mahasiswa mencari sumber bahan ajar lain melaui internet.

Sehubung dengan diterbitkannya Kualifikasi Nasional Indonesia (KKNI) dan Peraturan Presiden No.8 Tahun 2012 serta Undang-Undang No.12 Tahun 2012 Mengenai Pendidikan Tinggi, seluruh perguruan tinggi diwajibkan untuk menyesuaikan kurikulum dan bahan ajar-nya agar sesuai dengan perkembangan ilmu pengetahuan, teknologi serta dinamika perkembangan global abad 21 dan industri 4.0 [5]. Maka, revolusi industri juga memberikan perubahan pada bidang pendidikan [6], serta peningkatan jumlah penelitian tiap tahunnya mencerminkan bukti bahwa para akademisi mulai mengarahkan fokus penelitiannya pada industri 4.0 [7].

Contoh dari perkembangan teknologi di Indonesia salah satunya adalah pemanfaatan gawai yang sangat berpengaruh pada proses pembelajaran dan menjadi media yang mudah digunakan [8]. Namun, ketersediaan pembelajaran yang dapat diakses melalui gawai oleh peserta didik masih terbatas, hal ini menjadi penyebab kurangnya pemanfaatan teknologi informasi pada keperluan akademis [9]. Padahal perkembangan dalam hal alat, media pembelajaran serta hal-hal yang dapat menunjang pendidikan sangatlah penting untuk diimplementasikan dan diterapkan [10]. Maka tenaga pendidik dituntut harus memiliki kemampuan dalam hal teknologi yang sedang berkembang supaya bahan ajar yang digunakan dalam proses pembelajaran dapat diperbaharui sesuai hal tersebut [11].

Bahan ajar merupakan sesuatu yang dirancang sebagai alat yang dapat membantu pendidik dan peserta didik dalam proses pembelajaran sehingga pembelajaran lebih efektif [12]. Bahan ajar yang menarik, berbasis digital dan bermuatan landasan ilmu pendidikan menjadi hal yang dibutuhkan oleh peserta didik [13]. Selain itu bahan ajar menjadi faktor penentu dari keberhasilan proses pembelajaran dan bahan ajar yang dapat mendukung proses pembelajaran adalah modul [14].

Modul merupakan sarana pembelajaran yang disusun secara sistematis dalam bentuk tertulis atau cetak [15]. Namun, modul yang berbentuk cetak memiliki kelemahan karena tidak dapat mengakses video dan membuat pembelajaran tidak interaktif yang membuat peserta didik lebih cepat merasa bosan [16]. Agar terlibat aktif dalam setiap proses pembelajaran serta dapat memanfaatkan waktu dan membuat siswa lebih mandiri maka modul cetak harus disesuaikan dengan pemanfaatan teknologi.

Produk dari teknologi digital memberikan alternatif bahan ajar yang dapat digunakan dan diakses peserta didik dalam bentuk digital yaitu modul elektronik. Menurut Savira, dkk. modul elektronik dapat memudahkan siswa dalam mempelajari dan memahami materi, konsep, serta membuat pembelajaran menjadi menarik, interaktif, dan pembelajaran semakin efisien [17]. Pengguna dari modul elektronik dapat belajar dengan atau tanpa seorang fasilitator, guru, atau dosen [18]. Berdasarkan pernyataan tersebut bahan ajar modul elektronik yang disusun secara sistematis dan menarik dapat meningkatkan motivasi belajar dan mempermudah mahasiswa untuk mempelajari materi secara mandiri. Selain itu modul elektronik dapat digunakan melalui gawai. Sehingga dengan adanya bahan ajar modul elektronik yang menarik dan sesuai dengan isi materi dapat memberikan inovasi terhadap mata kuliah Statistika.

Berdasarkan hasil analisis kebutuhan awal, dapat disimpulkan bahwa mata kuliah Statistika membutuhkan penambahan materi dan dengan teknologi yang berkembang maka bahan ajar modul elektronik dapat diterapkan. Persentase yang didapat adalah 67,4\% dari 43 responden menyatakan bahwa modul elektronik cocok untuk digunakan pada mata kuliah Statistika. Penggunaan modul elektronik yang dapat diakses menggunakan gawai dimana saja dan kapan saja disertai dengan link yang akan terhubung dengan video diharapkan memberi kemudahan pada proses pembelajaran. Selain itu, pada penelitian yang sudah dilakukan bahwa modul elektronik sangat efektif pada proses pembelajaran [19].

Berdasarkan uraian diatas, maka perlu dilakukan penelitian pengembangan yang menghasilkan modul elektronik mata kuliah Statistika sehingga diharapkan penggunaan bahan ajar dapat membantu dosen dalam menyampaikan materi kuliah dan mempermudah mahasiswa memahami materi pada kuliah tersebut. 


\section{METODELOGI PENELITIAN}

Penelitian ini menggunakan metode penelitian dan pengembangan (Research and Development) dengan model pengembangan ADDIE. Model pengembangan ini terdiri dari 5 tahapan, yaitu analisis, perancangan, pengembangan, penerapan dan evaluasi. Penelitian ini dilaksanakan di Program Studi Pendidikan Teknik Bangunan, Fakultas Teknik, Universitas Negeri Jakarta dan dilaksanakan pada bulan Maret sampai dengan Desember 2020 dengan subjek penelitian mahasiswa prodi Pendidikan Teknik Bangunan. Penelitian pengembangan modul elektronik ini menggunakan instrumen dalam bentuk angket yang digunakan untuk memperoleh data yang dibutuhkan. Instrumen yang digunakan menggunakan skala Likert 5 yang ditujukan untuk mengetahui kualitas modul elektronik pembelajaran yang dikembangkan sudah layak digunakan atau belum dengan disertai dengan saran.

\section{HASIL DAN PEMBAHASAN}

Pada tahap analisis dilakukan analisis kebutuhan untuk mengembangkan bahan ajar Statistika dengan memberi kuesioner kepada beberapa orang yang telah mengikuti mata kuliah Statistika. Kuesioner diisi menggunakan google form pada Maret 2020 dengan jumlah responden 43 orang.

Perancangan modul elektronik berdasarkan RPS mata kuliah Statistika. Pada tahap perancangan modul elektronik Statistika menggunakan sistematika penulisan menurut Kemendikbud tahun 2017. Materi pada modul elektronik yang dikembangkan berjumlah 7 materi sesuai dengan RPS mata kuliah Statistika. Perancangan instrumen dilakukan sebelum proses penilaian oleh para ahli terhadap produk modul elektronik yang sudah dibuat. Penilaian media dilihat dari aspek tampilan dan penggunaan, sedangkan penilaian materi dilihat dari aspek isi, bahasa, penyajian dan evaluasi.

Penilaian dari aspek tampilan media diperoleh hasil persentase $82 \%$ dan aspek penggunaan diperoleh hasil persentase 93\%, sehingga dari seluruh penilaian aspek media pada modul elektronik Statistika diperoleh hasil persentase rata-rata $87 \%$ dengan kategori "sangat layak". Persentase rata-rata yang dihasilkan dari seluruh materi modul dengan tiga validator pada aspek materi adalah $80 \%$ dengan kategori "layak". Kelebihan lain berdasarkan hasil validasi dengan para ahli menyatakan bahwa modul elektronik yang dikembangkan secara keseluruhan tampilan cukup baik, modul mudah dalam penggunaan, serta pemetaan materi yang sudah baik dan sistematis. Tampilan modul dapat dilihat pada Gambar 1.

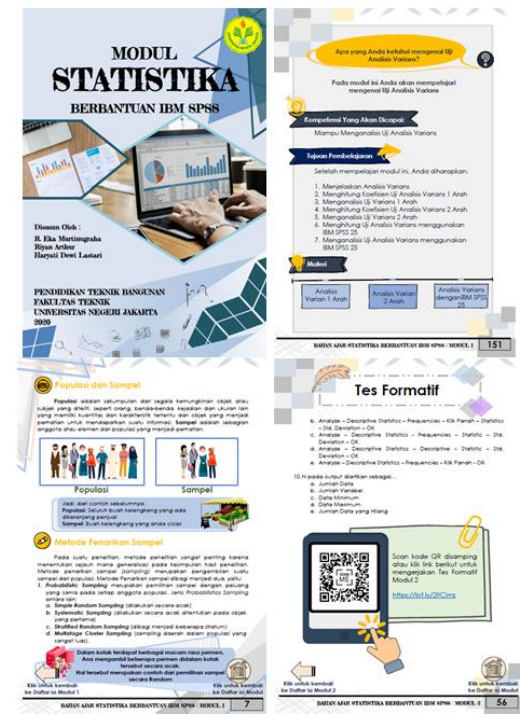

Gambar 1. Tampilan Modul Elektronik Statistika

Penyusunan modul elektronik yang dikembangkan menggunakan perangkat lunak Adobe InDesign. Pada modul elektronik terdapat tampilan yang berbeda pada setiap materi. Pemanfaatan hyperlink atau tombol navigasi juga diterapkan pada modul elektronik statistika untuk mempermudah pengguna dalam mengoperasikan materi perkuliahan yang sedang dan akan dipelajari maupun mengulang pada materi sebelumnya. Hyperlink diterapkan pada peta konsep, daftar isi, tombol kembali kehalaman sebelumnya dan tombol home untuk kembali ke daftar isi. Selain itu terdapat link dan $Q R$ code yang dapat digunakan pengguna untuk mengakses 
video pembelajaran di youtube sehingga dapat menunjang materi yang sedang dipelajari dan mengakses jurnal penelitian yang relevan dengan program studi Pendidikan Teknik Bangunan serta mengakses tes formatif diakhir materi. Pada pengembangan materi pembelajaran adalah penggunaan software SPSS sebagai aplikasi pengolah data statistika. Sehingga, mahasiswa dapat dengan mudah membandingkan perhitungan statistika secara manual dan menggunakan software SPSS. Terdapat link untuk mengerjakan soal tes formatif pilihan ganda sehingga mahasiswa dapat menerima feedback yaitu nilai dari hasil mengerjakan tes formatif melalui google form secara langsung.

Proses uji coba dilakukan secara terbatas kepada 10 orang mahasiswa dengan mengisi soal pre-test sebelum menggunakan modul, setelah itu diberikan modul elektronik Statistika untuk dipelajari sebelum mengisi soal post-test. Terdapat 30 soal pilihan ganda pada uji coba modul elektronik Statistika, soal dapat diakses dan diisi melalui google form. Hasil dari uji coba yang dilakukan mengalami kenaikan pada nilai posttest sebesar 25,8\% dimana terdapat perbedaan pada penggunaan modul elektronik Statistika.

Pada tahap evaluasi dilakukan perbaikan kepada modul elektronik berdasarkan saran dari para ahli media dan ahli materi. Saran yang diberikan untuk modul elektronik Statistika adalah perlunya penambahan contoh penelitian yang relevan dengan prodi Pendidikan Teknik Bangunan. Evaluasi penerapan didapatkan hasil bahwa terdapat peningkatan setelah menggunakan modul elektronik.

\section{PENUTUP}

\section{KESIMPULAN}

Berdasarkan penelitian pengembangan ini adalah untuk menghasilkan bahan ajar berbasis modul elektronik pada Mata Kuliah Statistika di Program Studi Pendidikan Teknik Bangunan Universitas Negeri Jakarta yang diharapkan dapat membantu proses pembelajaran maupun penelitian mahasiswa.

Pada proses validasi 7 materi pada modul elektronik dilakukan dengan tiga ahli media dan didapatkan nilai rata-rata persentase $87 \%$ dengan kategori "Sangat Layak" dan dengan tiga ahli materi didapatkan nilai rata-rata persentase $80 \%$ dengan kategori "Layak". Pada uji coba terbatas yang telah dilakukan terdapat kenaikan nilai sebesar $25,8 \%$ pada soal post-test atau setelah penggunaan modul elektronik Statistika. Sehingga, dapat disimpulkan bahan ajar berbasis modul elektronik pada Mata Kuliah Statistika di Program Studi Pendidikan Teknik Bangunan Universitas Negeri Jakarta layak digunakan.

\section{SARAN}

Hasil pengembangan modul elektronik dapat digunakan sebagai variasi bahan ajar dan di terapkan pada mata kuliah Statistika. Modul elektronik dapat dikembangkan lebih lanjut dengan menambahkan fitur audio, animasi dan bookmark serta evaluasi pembelajaran pada modul elektronik dapat dikembangkan dengan menambahkan keberagaman tes formatif. Modul elektronik dapat menjadi acuan untuk pengembangan menjadi media pembelajaran seperti multimedia interaktif dan video pembelajaran.

\section{DAFTAR PUSTAKA}

[1] M. D. Hutapea, "Penggunaan Metode Belajar Berbasis Problem Based Learning Untuk Menaikan Ketuntasan Hasil Belajar Siswa Pada Pembelajaran Program Linear di Kelas XII IPA-1 Semester Ganjil SMA Negeri 1 Pinangsori Tahun Pelajaran 2017/2018," J. Penelit. Tindakan Kelas dan Pengemb. Pembelajaran, vol. 1, no. 2, hal. 2018, 2018.

[2] J. Fajrin, Hariyadi, dan N. Marchelina, "Aplikasi Metode Eksperimen Response Surface untuk Mengoptimalkan Kuat Tekan Bata Non Bakar," J. Reka, vol. 13, no. 2, hal. 79-90, 2017.

[3] F. Febrinita, W. D. Puspitasari, dan S. Kirom, "Pengembangan Modul Mata Kuliah Statistika yang Terintegrasi Dengan Microsoft Excel dan SPSS Menggunakan Pendekatan Kecerdasan Linguistik," Pi Math. Educ. J., vol. 2, no. 2, hal. 88-97, 2019.

[4] L. Sufiyah dan H. Sumarsono, "Pengembangan media pembelajaran modul elektronik interaktif pada mata kuliah ekonomi untuk kelas X lintas minat ekonomi sma laboratorium UM Kota Malang," JPE, vol. 8, no. 2, hal. 64-74, 2015.

[5] Indonesia, “PP RI Nomor 8," 2012. 
[6] R. I. T. K. Negara, T. Iriani, dan Lenggogeni, "Pengembangan Multimedia Interaktif Pada Mata Kuliah Manajemen Konstruksi di S1 Pendidikan Teknik Bangunan Universitas Negeri Jakarta," J. PenSil, vol. 8, no. 2, hal. 55-104, 2019.

[7] H. Prasetyo dan W. Sutopo, "Industri 4.0: Telaah Klasifikasi Aspek dan Arah Perkembangan Riset," J@ti Undip J. Tek. Ind., vol. 13, no. 1, hal. 17-26, 2018.

[8] A. Amalia, S. N. Handayani, Y. Rostikawati, dan A. A. R. R, "Dampak Penggunaan Gawai Terhadap Hasil Belajar Mahasiswa IKIP Siliwangi," Parol. (Jurnal Pendidik. Bhs. dan Sastra Indones., vol. 1, no. 2, hal. 157164, 2018.

[9] R. Arthur, Y. Luthfiana, dan S. Musalamah, "Analisa Kebutuhan Pengembangan Media Pembelajaran Pada Mata Kuliah Mekanika Bahan di Universitas Negeri Jakarta," vol. 5, no. 2, hal. 38-44, 2019.

[10] Nopriadi, Darlius, dan I. Syofii, "Pengembangan Bahan Ajar Berbasis Modul Elektronik Program Studi Pendidikan Teknik Mesin Universitas Sriwijaya 2015," hal. 126-135, 2015.

[11] H. M. Khoir, R. E. Murtinugraha, dan S. Musalamah, "Pengembangan Media Pembelajaran E-Learning Berbasis Moodle Pada Mata Kuliah Metodologi Penelitian,” J. PenSil, vol. 9, no. 1, hal. 1-7, 2020.

[12] A. Asrizal, A. Amran, A. Ananda, dan F. Festiyed, "Effectiveness of Adaptive Contextual Learning Model of Integrated Science by Integrating Digital Age Literacy on Grade VIII Students," IOP Conf. Ser. Mater. Sci. Eng., 2018.

[13] M. T. Cahyati, E. A. Usman, dan Y. A. Putri, "Meta-Analisis Implementasi Landasan Ilmu Pendidikan terhadap Pengembangan Bahan Ajar dalam Pembelajaran Fisika pada Era Revolusi Industri 4 . 0 ," J. Penelit. Pembelajaran Fis., vol. 5, no. 1, hal. 34-41, 2019.

[14] S. Devesh dan D. A. L. Nasseri, "Effectiveness of Mathematics Module in Foundation Programme in Majan College," Int. J. Emerg. Eng. Res. Technol., vol. 2, no. 1, hal. 1-7, 2014.

[15] Hamdani, Strategi Belajar Mengajar. Bandung: CV Pustaka Setia, 2011.

[16] A. D. Puspitasari, "Penerapan Media Pembelajaran Fisika Menggunakan Modul Cetak dan Modul Elektronik Pada Siswa SMA," J. Pendidik. Fis., vol. 7, no. 1, hal. 17-25, 2019.

[17] Y. M. Savira, A. S. Budi, dan Y. Supriyati, "Pengembangan E-Modul Materi Momentum dan Impuls Berbasis Process Oriented Guided Inquiry Learning (POGIL) Untuk Meningkatkan Kemampuan Berpikir," Pros. Semin. Nas. Fis. SNF2019, vol. VIII, hal. 25-36, 2019.

[18] A. Prastowo, Panduan Kreatif Membuat Bahan Ajar Inovatif; Menciptakan Metode Pembelajaran yang Menarik dan Menyenangkan. Yogyakarta: DIVA Pers, 2011.

[19] T. H. Hawsawi, E. Al-naghshabandi, dan S. M. Sofar, "Effectiveness of Electronic Learning Module in Implementing Ventilator- Associated Pneumonia Prevention Measures of Intensive Care Unit Nurses Taghreed," vol. 2, no. 2, hal. 1-9, 2018.

[20] K. P. dan K. Nasional, D. P. SMA, dan D. J. P. D. dan Menengah, Panduan Praktis Penyusunan e-Modul Pembelajaran. 2017. 